\title{
Associations between novel genetic variants in the promoter region of MALAT1 and risk of colorectal cancer
}

\author{
Yingjun $\mathrm{Li}^{1,2}$, Chengzhen $\mathrm{BaO}^{1}$, Simeng $\mathrm{Gu}^{1}$, Ding $\mathrm{Ye}^{1}$, Fangyuan Jing ${ }^{2}$, Chunhong \\ Fan $^{2}$, Mingjuan Jin ${ }^{1}$ and Kun Chen ${ }^{1}$ \\ ${ }^{1}$ Department of Epidemiology and Health Statistics, Zhejiang University School of Public Health, Hangzhou, China \\ ${ }^{2}$ Department of Public Health, Hangzhou Medical College, Hangzhou, China \\ Correspondence to: Kun Chen, email: ck@zju.edu.cn
}

Keywords: InCRNA, MALATI, genetic variants, colorectal cancer

Received: March 01, $2017 \quad$ Accepted: August 29, $2017 \quad$ Published: October 04, 2017

Copyright: Li et al. This is an open-access article distributed under the terms of the Creative Commons Attribution License 3.0 (CC BY 3.0), which permits unrestricted use, distribution, and reproduction in any medium, provided the original author and source are credited.

\section{ABSTRACT}

The metastasis-associated lung adenocarcinoma transcript 1 (MALAT1), a wellknown long non-coding RNA, is involved in pathogenesis and progress of multiple tumors. However, no study has been performed to investigate the relationship between the genetic variants in promoter region of MALAT1 and colorectal cancer risk. In this study, we conducted a two-stage case-control study to evaluate whether MALAT1 genetic variants were associated with colorectal cancer risk. We identified that a single nucleotide polymorphism (SNP) rs1194338 was significantly associated with the decreased colorectal cancer risk with an odds ratio (OR) of 0.70 [95\% confidence interval $(\mathrm{CI})=0.49-0.99$ ] in the combined stage. The subsequently stratified analyses showed that the protective effect of rs1194338 was more pronounced in several subgroups. Furthermore, gene expression profiling analysis revealed overexpression of MALAT1 MRNA in colorectal cancer tissue compared with normal controls. Confirmation studies with large sample size and further mechanistic investigations into the function of MALAT1 and its genetic variants are warranted to advance our understanding of their roles in colorectal carcinogenesis, and to aid in the development of novel and targeted therapeutic strategies.

\section{INTRODUCTION}

Long non-coding RNAs (lncRNAs), defined as RNA molecules greater than 200 nucleotides in length, have gained much attention due to their crucial roles as epigenetic regulators of gene expression [1]. Recently, increasing numbers of studies have reported that lncRNAs are dysregulated in many complex diseases, such as ischemic stroke [2], Alzheimer's disease [3], heart disease [4] and cancers [5, 6]. Especially, the metastasisassociated lung adenocarcinoma transcript 1 (MALAT1) which is transcribed from nuclear-enriched transcript 2 (NEAT2), is a novel $8.1 \mathrm{~kb}$ long non-coding RNA [7]. It is located at chromosome 11q13.1, and is highly expressed in various types of human tissues. Progressing findings have suggested that MALAT1 activates the development and progression of cancer by participating in multiple processes including cell proliferation, migration, invasion and apoptosis [7-10]. Also, Malakar et al. have indicated that MALAT1 promotes hepatocellular carcinoma development by serine/arginine-rich splicing factor 1 (SRSF1) upregulation and mammalian target of rapamycin (mTOR) activation [11]. Lee et al. have validated that, when compared with normal cell lines and tissues, the expression of MALAT1 is significantly elevated in various gastric cancer cell lines as well as gastric cancer tissues, and MALAT1 is involved in gastric tumorigenesis by inhibiting cell apoptosis and promoting cell invasiveness via the epithelial-to-mesenchymal transition [12]. Further study has shown that MALAT1 could promote gallbladder cancer development by acting as a molecular sponge to reduce the expression of miR- 
206 [13]. In colorectal cancer (CRC), the MALAT1 level is highly expressed in tumor and is associated closely with CRC invasion and metastasis [14]; besides, MALAT1 could motivate CRC cell proliferation, migration and invasion through PRKA kinase anchor protein 9 (AKAP-9) [15].

Recently, many epidemiologic studies have explored the link between genetic variants in lncRNAs and cancer susceptibility. Actually, it has been shown that among the identified genetic variants which are associated with multiple traits or diseases, $43 \%$ of them are intergenic and $45 \%$ are intronic according to a multifaceted analysis of published genome-wide association studies [16]. For example, the single nucleotide polymorphism (SNP) rs2147578 in lnc-LAMC2-1:1 is significantly associated with increased risk for CRC occurrence by inhibiting miRNA binding [17]. Besides, novel SNP rs16941835 in lncRNA RP11-58A18.1 has been newly identified to be associated with increased CRC risk in a genome-wide association study and meta-analysis [18]. Furthermore, Xue et al. have demonstrated that tag SNP rs7958904 in HOTAIR is related with decreased CRC risk and may act as a potential biomarker for predicting the risk of CRC [19]. Actually, several studies have demonstrated that lncRNA MALAT1 polymorphisms are related with different disease susceptibility [20,21]. Nevertheless, to the best of our knowledge, no study has been performed to evaluate the association between MALATI genetic variants and the risk of CRC.

Otherwise, as with that SNPs in protein-coding genes could play important roles in the development of complex human diseases by affecting gene expression and function [22, 23]; polymorphisms in promoter region of functional lncRNAs might also be associated with disease susceptibility by affecting the stability and efficiency of transcription, resulting in modulation of their interaction partners [24, 25]. Therefore, a two-stage casecontrol study was conducted to investigate the association between SNPs in promoter region of MALAT1 and CRC risk in a Chinese population.

\section{RESULTS}

\section{Characteristics of study population}

In the present study, we included a total of 821 CRC cases and 857 controls in two stages. There were no statistically significant differences between CRC cases and healthy controls in the combined stage relating to age, gender, body mass index (BMI), smoking and alcohol drinking (all $P>0.05$, Table 1). However, we found that higher percentage of patients reported a family history of cancer $(P<0.001)$ and non-tea drinking status $(P=0.016)$ when compared with healthy controls. Besides, $48.84 \%$ of included cases were colon cancer and $51.16 \%$ were rectal cancer.

\section{Associations of SNPs and CRC risk}

Table 2 shows the effects of four SNPs (i.e. rs4102217, rs591291, rs1194338 and rs600231) polymorphisms on CRC in Stage 1. The genotypes distributions of four SNPs among the controls were in accordance with Hardy-Weinberg equilibrium (HWE) $(P>0.01)$. Subsequently, we applied three genetic effect models to evaluate the associations between the selected SNPs and the risk of CRC. However, no statistically significant association between the four SNPs and CRC risk was observed. After adjustment for age, gender, BMI, smoking, alcohol and tea drinking, we found that genetic effect of SNP rs1194338 in dominant model was just barely insignificantly associated with decreased CRC risk $(P=0.113 ; \mathrm{OR}=0.77,95 \% \mathrm{CI}=0.55-1.06)$. Besides, rs1194338 CA genotype, but not AA genotype, had a nearborderline significant association with decreased risk of $\mathrm{CRC}$, compared with $\mathrm{CC}$ genotype $(P=0.101 ; \mathrm{OR}=0.75$, $95 \% \mathrm{CI}=0.54-1.06$ ).

In addition, we identified that rs1194338 was significantly associated with CRC risk in Stage 2 (Table 3). After adjustment for potential confounders, rs 1194338 variant allele $\mathrm{A}$ showed a statistically significant association with decreased CRC risk: the ORs were 0.63 (95\% CI: 0.41-0.97) for codominant model and 0.62 (95\% CI: 0.41-0.93) for recessive model. When combined these two stages, the AA genotype, but not CA genotype, had a statistically significant association with decreased risk of CRC, compared with CC genotype $(P=0.045 ; \mathrm{OR}=0.70$, 95\% CI $=0.49-0.99$ ).

Furthermore, stratified analyses relating to lifestylerelated characteristics and tumor site were performed. More pronounced risk effect of homozygous variant genotype of rs1194338 were found in subgroup of no history of cancer (AA vs. CC: $\mathrm{OR}=0.60,95 \% \mathrm{CI}=0.40$ 0.89 ), no habit of alcohol drinking (AA vs. CC: $\mathrm{OR}=$ $0.61,95 \% \mathrm{CI}=0.41-0.91$ ), and rectal cancer (AA vs. CC: $\mathrm{OR}=0.62,95 \% \mathrm{CI}=0.40-0.97)($ Figure 1$)$.

\section{Functional relevance of rs1194338 on $M A L A T 1$ expression level}

To further elucidate the potential molecular relevance of the association, the Oncomine expression profiling database was used to determine whether the expression of MALAT1 mRNA was altered in CRC tissue relative to controls. The $P$-value and the foldchange of each probe comparison between CRC tissue and normal controls were extracted to generate a volcano plot. As shown in Figure 2A, MALAT1 mRNA were overexpressed in CRC tissue compared with adjacent normal tissue or tissue from healthy controls. Moreover, the expression levels of MALAT1 were evaluated in $71 \mathrm{CRC}$ tissues samples. Among the 71 samples, 34 individuals carried the rs 1194338 CC genotype, 29 
Table 1: The demographic and lifestyle-related characteristics between the colorectal cancer cases and controls

\begin{tabular}{|c|c|c|c|c|c|c|c|}
\hline & \multicolumn{2}{|c|}{ Stage 1} & \multicolumn{2}{|c|}{ Stage 2} & \multicolumn{2}{|c|}{ Combined stage a } & \multirow{2}{*}{$P$} \\
\hline & Case $(n=320)$ & Control $(n=319)$ & Case $(n=501)$ & Control $(n=538)$ & Case $(n=821)$ & Control $(n=857)$ & \\
\hline Age $($ mean $\pm \mathrm{SD})$ & $65.76 \pm 10.23$ & $65.30 \pm 9.76$ & $62.73 \pm 10.99$ & $62.26 \pm 10.53$ & $63.91 \pm 10.79$ & $63.39 \pm 10.35$ & 0.316 \\
\hline \multicolumn{8}{|l|}{ Gender, $N(\%)$} \\
\hline Male & $168(52.50)$ & $157(49.22)$ & $262(52.30)$ & $285(52.97)$ & $430(52.38)$ & $442(51.58)$ & 0.743 \\
\hline Female & $152(47.50)$ & $162(50.78)$ & $239(47.70)$ & $253(47.03)$ & $391(47.62)$ & $415(48.42)$ & \\
\hline \multicolumn{8}{|l|}{ BMI, $N(\%)$} \\
\hline$<18.5$ & $27(8.44)$ & $17(5.33)$ & $47(9.38)$ & $46(8.55)$ & $74(9.01)$ & $63(7.35)$ & 0.239 \\
\hline $18.5 \sim 23.9$ & $216(67.50)$ & $201(63.01)$ & $339(67.66)$ & $363(67.47)$ & $555(67.72)$ & $564(65.93)$ & \\
\hline $24 \sim 27.9$ & $61(19.06)$ & $85(26.65)$ & $99(19.76)$ & $113(21.00)$ & $160(19.37)$ & $198(23.10)$ & \\
\hline$\geq 28$ & $16(5.00)$ & $16(5.02)$ & $16(3.19)$ & $16(2.97)$ & $32(3.90)$ & $32(3.62)$ & \\
\hline \multicolumn{8}{|c|}{ Family history of cancer, $N(\%)$} \\
\hline No & $257(80.31)$ & $287(89.97)$ & $394(78.64)$ & $450(83.64)$ & $651(79.29)$ & $737(86.00)$ & $<0.001$ \\
\hline Yes & $63(19.69)$ & $30(9.40)$ & $107(21.36)$ & $88(16.36)$ & $170(20.71)$ & $118(13.77)$ & \\
\hline \multicolumn{8}{|l|}{ Smoking, $N(\%)$} \\
\hline No & $208(65.00)$ & $220(68.97)$ & $316(63.07)$ & $330(61.34)$ & $524(63.82)$ & $550(64.18)$ & 0.882 \\
\hline Yes & $112(35.00)$ & 99 (31.03) & $183(36.53)$ & $206(38.29)$ & $295(35.93)$ & 305 (35.59) & \\
\hline \multicolumn{8}{|c|}{ Alcohol drinking, $N(\%)$} \\
\hline No & $247(77.19)$ & $248(77.74)$ & $359(71.66)$ & $386(71.75)$ & $606(73.81)$ & $634(73.98)$ & 0.783 \\
\hline Yes & $72(22.50)$ & $68(21.32)$ & $138(27.54)$ & $145(26.95)$ & $210(25.58)$ & $213(24.85)$ & \\
\hline \multicolumn{8}{|c|}{ Tea drinking, $N(\%)$} \\
\hline No & $200(62.50)$ & $193(60.50)$ & $294(58.68)$ & $273(50.74)$ & $494(60.17)$ & $466(54.38)$ & 0.016 \\
\hline Yes & $120(37.50)$ & $126(39.50)$ & $201(40.12)$ & $259(48.14)$ & $321(39.10)$ & $385(44.92)$ & \\
\hline \multicolumn{8}{|l|}{ Tumor site } \\
\hline Colon & $157(49.06)$ & & $244(48.70)$ & & $401(48.84)$ & & \\
\hline Rectal & $163(50.94)$ & & $257(51.30)$ & & $420(51.16)$ & & \\
\hline
\end{tabular}

SD, standard deviation; BMI, body mass index; N, number

${ }^{a}$ Combine Stage 1 and Stage 2 as the combined stage

carried the CA genotype, and 8 carried the AA genotype. There was no statistically significant difference of MALAT1 expression between CC genotype and AA genotype in CRC tissues (Figure 2B). Thirdly, according to the Genome-Tissue Expression (GTEx) database [26], no statistically significant down-regulation of MALAT1 mRNA expression with rs1194338 variant genotype $(\mathrm{C} / \mathrm{A}+\mathrm{A} / \mathrm{A})$ compared with the wild-type homozygous genotype $(\mathrm{C} / \mathrm{C}, P=0.652$, Figure $2 \mathrm{C})$ was observed in 169 transverse colon tissues.

\section{DISCUSSION}

Colorectal cancer is among the most common gastrointestinal malignant neoplasms and represents the third cause of cancer morbidity and the fourth cause of cancer mortality worldwide, with 1.4 million new cases and 0.7 million deaths estimated to have occurred in 2012
[27]. The pathogenesis of CRC is a complex process that is tightly controlled by multiple layers of regulatory mechanisms, which entail the accumulation of both genetic and epigenetic alterations in proliferating cells [28]. In the current study, a two-stage case-control study was performed to investigate the effect of four MALAT1 SNPs on CRC risk. As a result, SNP rs1194338 in the promoter region of MALAT1 was significantly associated with decreased CRC risk, especially in the subgroup of no history of cancer, no habit of alcohol drinking, and rectal cancer. Gene expression profiling analysis revealed increased expression of MALAT1 in CRC tissue compared with normal controls. Taken together, this is the first study to explore the association between MALATl genetic variants and $\mathrm{CRC}$ risk and provide further evidence for the involvement of MALATI in CRC tumorigenesis.

Progressing findings have suggested a crucial role of lncRNAs in tumorigenesis. For example, HOTAIR 
Table 2: Association of the selected SNPs with colorectal cancer risk in Stage 1

\begin{tabular}{|c|c|c|c|c|c|}
\hline \multirow{2}{*}{ Variable } & \multirow{2}{*}{ Case $(\%)(n=320)$} & \multirow{2}{*}{ Control $(\%)(n=319)$} & \multirow{2}{*}{$\begin{array}{c}\text { Model 1 }{ }^{\text {a }} \\
\text { OR }(95 \% \text { CI })\end{array}$} & \multirow{2}{*}{$\frac{\text { Model } 2{ }^{\mathrm{b}}}{\text { OR }(95 \% \mathrm{CI})}$} & \multirow{2}{*}{$P$-value ${ }^{\mathrm{c}}$} \\
\hline & & & & & \\
\hline \multicolumn{6}{|c|}{$\mathrm{rs} 4102217\left(P_{\mathrm{HWE}}=0.20\right)$} \\
\hline \multicolumn{6}{|c|}{ Codominant model } \\
\hline GG & $235(73.67)$ & $246(77.12)$ & 1.00 & 1.00 & \\
\hline GC & $79(24.76)$ & $71(22.26)$ & $1.16(0.81-1.68)$ & $1.14(0.78-1.66)$ & 0.506 \\
\hline $\mathrm{CC}$ & $5(1.57)$ & $2(0.63)$ & - & - & - \\
\hline \multicolumn{6}{|c|}{ Dominant model } \\
\hline GG & 235 (73.67) & $246(77.12)$ & 1.00 & 1.00 & \\
\hline $\mathrm{GC}+\mathrm{CC}$ & $84(26.33)$ & $73(22.88)$ & $1.20(0.84-1.73)$ & $1.19(0.82-1.73)$ & 0.366 \\
\hline \multicolumn{6}{|c|}{ Recessive model } \\
\hline $\mathrm{GG}+\mathrm{GC}$ & $314(98.43)$ & $317(99.37)$ & 1.00 & 1.00 & \\
\hline $\mathrm{CC}$ & $5(1.57)$ & $2(0.63)$ & - & - & - \\
\hline \multicolumn{6}{|c|}{$\operatorname{rs} 591291\left(P_{\mathrm{HWE}}=0.63\right)$} \\
\hline \multicolumn{6}{|c|}{ Codominant model } \\
\hline $\mathrm{CC}$ & $119(37.42)$ & $112(35.44)$ & 1.00 & 1.00 & \\
\hline $\mathrm{CT}$ & $150(47.17)$ & $156(49.37)$ & $0.90(0.64-1.27)$ & $0.86(0.60-1.24)$ & 0.421 \\
\hline $\mathrm{TT}$ & $49(15.41)$ & $48(15.19)$ & $0.96(0.60-1.54)$ & $0.93(0.57-1.52)$ & 0.762 \\
\hline \multicolumn{6}{|c|}{ Dominant model } \\
\hline $\mathrm{CC}$ & $119(37.42)$ & $112(35.44)$ & 1.00 & 1.00 & \\
\hline $\mathrm{CT}+\mathrm{TT}$ & $199(62.58)$ & $204(64.56)$ & $0.92(0.66-1.27$ & $0.88(0.63-1.23)$ & 0.453 \\
\hline \multicolumn{6}{|c|}{ Recessive model } \\
\hline $\mathrm{CC}+\mathrm{CT}$ & $269(84.59)$ & $268(84.81)$ & 1.00 & 1.00 & \\
\hline TT & $49(15.41)$ & $48(15.19)$ & $1.02(0.66-1.57)$ & $1.01(0.64-1.58)$ & 0.977 \\
\hline \multicolumn{6}{|c|}{$\operatorname{rs} 1194338\left(P_{\mathrm{HWE}}=0.02\right)$} \\
\hline \multicolumn{6}{|c|}{ Codominant model } \\
\hline $\mathrm{CC}$ & $152(47.50)$ & $134(42.54)$ & 1.00 & 1.00 & \\
\hline $\mathrm{CA}$ & $141(44.06)$ & $157(49.84)$ & $0.79(0.57-1.10)$ & $0.75(0.54-1.06)$ & 0.101 \\
\hline AA & $27(8.44)$ & $24(7.62)$ & $0.99(0.55-1.80)$ & $0.86(0.46-1.61)$ & 0.639 \\
\hline \multicolumn{6}{|c|}{ Dominant model } \\
\hline $\mathrm{CC}$ & $152(47.50)$ & $134(42.54)$ & 1.00 & 1.00 & \\
\hline $\mathrm{CA}+\mathrm{AA}$ & $168(52.50)$ & $181(57.46)$ & $0.82(0.60-1.12)$ & $0.77(0.55-1.06)$ & 0.113 \\
\hline \multicolumn{6}{|c|}{ Recessive model } \\
\hline $\mathrm{CC}+\mathrm{CA}$ & $293(91.56)$ & $291(92.38)$ & 1.00 & 1.00 & \\
\hline AA & $27(8.44)$ & $24(7.62)$ & $1.11(0.63-1.98)$ & $1.00(0.55-1.82)$ & 0.992 \\
\hline \multicolumn{6}{|c|}{$\operatorname{rs} 600231\left(P_{\mathrm{HWE}}=0.44\right)$} \\
\hline \multicolumn{6}{|c|}{ Codominant model } \\
\hline AA & $118(36.88)$ & $111(34.91)$ & 1.00 & 1.00 & \\
\hline AG & $152(47.50)$ & $160(50.31)$ & $0.89(0.64-1.26)$ & $0.83(0.58-1.19)$ & 0.320 \\
\hline GG & $50(15.62)$ & $47(14.78)$ & $1.00(0.62-1.61)$ & $0.94(0.57-1.54)$ & 0.798 \\
\hline \multicolumn{6}{|c|}{ Dominant model } \\
\hline AA & $118(36.88)$ & $111(34.91)$ & 1.00 & 1.00 & \\
\hline $\mathrm{AG}+\mathrm{GG}$ & $202(63.12)$ & $207(65.09)$ & $0.92(0.66-1.27)$ & $0.86(0.61-1.20)$ & 0.376 \\
\hline \multicolumn{6}{|c|}{ Recessive model } \\
\hline $\mathrm{AA}+\mathrm{AG}$ & $270(84.38)$ & $271(85.22)$ & 1.00 & 1.00 & \\
\hline GG & $50(15.62)$ & $47(14.78)$ & $1.06(0.69-1.64)$ & $1.04(0.66-1.63)$ & 0.864 \\
\hline
\end{tabular}


Table 3: Association of rs1194338 with colorectal cancer risk in Stage 2 and combined stage

\begin{tabular}{|c|c|c|c|c|c|}
\hline \multirow{2}{*}{ Variable } & \multirow{2}{*}{ Case $(\%)(n=501)$} & \multirow{2}{*}{ Control $(\%)(n=538)$} & \multirow{2}{*}{$\frac{\text { Model } 1^{\mathrm{a}}}{\text { OR }(95 \% \mathrm{CI})}$} & \multirow{2}{*}{$\begin{array}{c}\text { Model 2 }^{\mathrm{b}} \\
\text { OR }(95 \% \text { CI) }\end{array}$} & \multirow{2}{*}{$P$-value } \\
\hline & & & & & \\
\hline \multicolumn{6}{|c|}{ rs1194338 $\left(P_{\mathrm{HWE}}=0.67\right)$} \\
\hline \multicolumn{6}{|c|}{ Codominant model } \\
\hline $\mathrm{CC}$ & $237(47.59)$ & $247(45.91)$ & 1.00 & 1.00 & \\
\hline $\mathrm{CA}$ & $216(43.37)$ & $220(40.89)$ & $1.02(0.79-1.33)$ & $1.06(0.81-1.38)$ & 0.690 \\
\hline AA & $45(9.04)$ & $71(13.20)$ & $0.66(0.44-1.00)$ & $0.63(0.41-0.97)$ & 0.036 \\
\hline \multicolumn{6}{|c|}{ Dominant model } \\
\hline $\mathrm{CC}$ & $237(47.59)$ & $247(45.91)$ & 1.00 & 1.00 & \\
\hline $\mathrm{CA}+\mathrm{AA}$ & $261(52.41)$ & $291(54.09)$ & $0.94(0.73-1.19)$ & $0.95(0.74-1.22)$ & 0.685 \\
\hline \multicolumn{6}{|c|}{ Recessive model } \\
\hline $\mathrm{CC}+\mathrm{CA}$ & $453(90.96)$ & $467(86.80)$ & 1.00 & 1.00 & \\
\hline AA & $45(9.04)$ & $71(13.20)$ & $0.65(0.44-0.97)$ & $0.62(0.41-0.93)$ & 0.021 \\
\hline \multicolumn{6}{|c|}{ Combined stage } \\
\hline & Case(\%) $(\mathrm{n}=821)$ & Control (\%) (n=857) & & & \\
\hline \multicolumn{6}{|l|}{ rs1194338 } \\
\hline \multicolumn{6}{|c|}{ Codominant model } \\
\hline $\mathrm{CC}$ & $389(47.56)$ & $381(44.67)$ & 1.00 & 1.00 & \\
\hline $\mathrm{CA}$ & $357(43.64)$ & $377(44.20)$ & $0.92(0.75-1.13)$ & $0.91(0.65-1.27)$ & 0.115 \\
\hline $\mathrm{AA}$ & $72(8.80)$ & $95(11.14)$ & $0.75(0.54-1.06)$ & $0.70(0.49-0.99)$ & 0.045 \\
\hline \multicolumn{6}{|c|}{ Dominant model } \\
\hline $\mathrm{CC}$ & $389(47.56)$ & $381(44.67)$ & 1.00 & 1.00 & \\
\hline $\mathrm{CA}+\mathrm{AA}$ & $429(52.44)$ & $472(55.33)$ & $0.89(0.74-1.08)$ & $0.88(0.72-1.07)$ & 0.205 \\
\hline \multicolumn{6}{|c|}{ Recessive model } \\
\hline $\mathrm{CC}+\mathrm{CA}$ & $746(91.20)$ & $758(88.86)$ & 1.00 & 1.00 & \\
\hline AA & $72(8.80)$ & $95(11.14)$ & $0.82(0.48-1.37)$ & $0.75(0.47-1.18)$ & 0.213 \\
\hline
\end{tabular}

HWE, Hardy-Weinberg equilibrium

${ }^{a}$ Crude Model

${ }^{\mathrm{b}}$ Adjusted for age, gender, BMI, smoking, alcohol and tea drinking

${ }^{\mathrm{c}} P$-value for adjusted model

could affect gene transcription and involve malignance by interacting with chromatin-remodeling complexes as well as recruiting these complexes to specific genomic DNA sequences [29, 30]. Besides, IncRNAs PRNCR1 and $P C G E M 1$, specifically interact with androgen receptor (AR) and strongly enhance androgen receptor-mediated gene activation in both ligand-dependent and ligandindependent manner [31]. Another IncRNA, H19 could promote tumor metastasis by regulating critical events including the epithelial-to-mesenchymal transition and the mesenchymal-to-epithelial transition [32]. Some reports have shown that MALAT1 could regulate the expression of metastasis-associated genes as well as cell cycle genes [33], and perform key roles in G1/S and mitotic progression [34]. Furthermore, MALAT1-depleted cells show cell cycle defects which are sensitive to the p53 levels, indicating that $\mathrm{p} 53$ is a main downstream mediator for the MALAT1 activity [34].

Genetic variants in lncRNAs could be associated with the development and progression of multiple diseases by influencing their expressions or functions [35]. The promoter, a regulatory region of DNA located upstream of a gene, plays an important role in transcriptional regulation [36]. Thus, it is believed that genetic variants 
in promoter region can affect the expression, stability and subcellular localization of transcriptome, resulting in function changes and disease occurrence [37]. In our study, we observed the association between SNP rs1194338 in MALAT1 promote region and the decreased risk of CRC. However, the rs1194338 polymorphism $(\mathrm{C}>\mathrm{A})$ did not affect the expression levels of MALAT1 neither in transverse colon tissues nor in CRC tissues based on bioinformatics analysis and quantitative RT-PCR. We hypothesized that some of the common variants might change the cell-to-cell variability, temporal dynamics or cell cycle dependence of gene expression at the singlecell level, instead of influencing the average gene expression of a gene in a whole tissue [38]. It may also because of that many regulatory genetic variants display functionality only after pathophysiologically relevant

\begin{tabular}{|c|c|c|c|}
\hline CC vs. AA & & OR $(95 \% \mathrm{CI})$ & $P$ value \\
\hline $\begin{array}{l}\text { Family history of cancer } \\
\text { No } \\
\text { Yes }\end{array}$ & 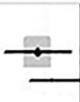 & $\begin{array}{l}0.60(0.40,0.89) \\
1.57(0.54,4.56)\end{array}$ & $\begin{array}{l}0.012 \\
0.408\end{array}$ \\
\hline $\begin{array}{l}\text { Smoking } \\
\text { No } \\
\text { Yes }\end{array}$ & $\because$ & $\begin{array}{l}0.71(0.47,1.08) \\
0.81(0.44,1.50)\end{array}$ & $\begin{array}{l}0.121 \\
0.511\end{array}$ \\
\hline $\begin{array}{l}\text { Alcohol drinking } \\
\text { No } \\
\text { Yes }\end{array}$ & $\rightarrow$ & $\begin{array}{l}0.61(0.41,0.91) \\
0.87(0.40,1.89)\end{array}$ & $\begin{array}{l}0.036 \\
0.730\end{array}$ \\
\hline $\begin{array}{l}\text { Tea drinking } \\
\text { No } \\
\text { Yes }\end{array}$ & $\stackrel{5}{2}$ & $\begin{array}{l}0.67(0.43,1.05) \\
0.75(0.42,1.34)\end{array}$ & $\begin{array}{l}0.084 \\
0.334\end{array}$ \\
\hline $\begin{array}{l}\text { Tumor site } \\
\text { Colon } \\
\text { Rectal }\end{array}$ & $\underset{\leftarrow}{\rightleftarrows}$ & $\begin{array}{l}0.85(0.53,1.35) \\
0.62(0.40,0.97)\end{array}$ & $\begin{array}{l}0.479 \\
0.037\end{array}$ \\
\hline
\end{tabular}

Figure 1: Forest plot shows odds ratio for the association between $M A L A T 1$ rs1194338 polymorphism and the risk of colorectal cancer stratified by lifestyle-related characteristics and tumor site (AA vs. CC).

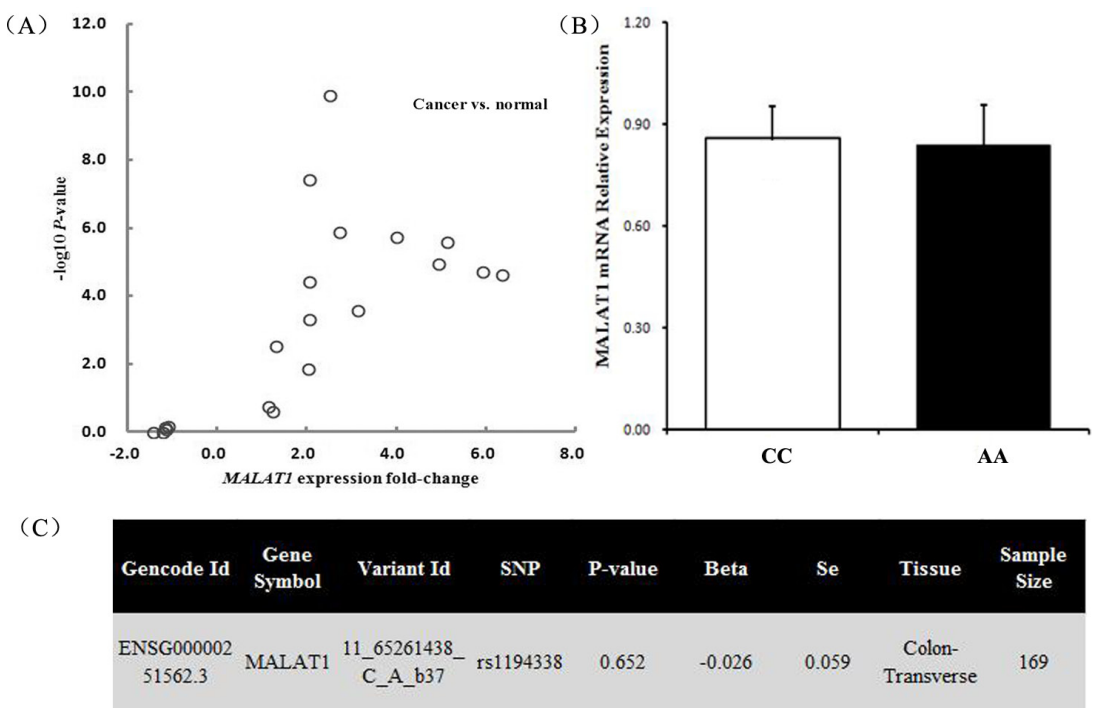

Figure 2: Functional relevance of rs1194338 on $\boldsymbol{M A L A T 1}$ expression level. (A) Expression analysis of $M A L A T 1$ in colorectal cancer tissue and normal controls from Oncomine database. Volcano plots were generated using the $P$-value and fold-change of each probe comparison; (B) relative expression level of MALAT1 mRNA grouped by rs1194338 CC and rs1194338 AA genotypes in 71 colorectal cancer tissues: there was no statistically significant difference between CC and AA genotypes; (C) correlation between MALAT1 mRNA expression and rs 1194338 polymorphism in 169 transverse colon tissues according to the Genome-Tissue Expression (GTEx) database. 
immune stimuli. It is possible to more extensively resolve functional genetic variants and the specific modulated genes associated with cancer by considering the cellular and environmental context relevant to cancer [39]. Thus, we could not detect the direct correlation between the rs1194338 polymorphism and MALAT1 mRNA expression level in the present study. Further studies are needed to investigate the precise mechanism underlying the function of the synonymous substitution.

There are some limitations in this study. One of the limitations is the recall bias, which is inevitable in casecontrol studies. However, as recall bias would not affect the genotype, it is of less concern in genetic association studies. On the other hand, the observed associations of our study might have insufficient statistical power due to the relatively moderate sample size [21]. However, we used a two-stage investigation to validate the association between the genetic variants and CRC susceptibility. Thirdly, information about clinical and pathological characteristics was unavailable in the current study, which might confine the representativeness of our findings. It is widely accepted that clinical and pathological characteristics are commonly related to many distinct molecular biological events, which could delineate the tumor development to some extent [40]. For example, the TNM staging could involve distinct molecular signatures reflecting the stepwise progression of CRC [41].

In conclusion, the findings from our two-stage population-based genetic association analysis provide the first evidence of the association between IncRNA MALATI rs1194338 polymorphism and colorectal carcinogenesis. The variant genotype (AA) of rs1194338 decreased CRC risk. Furthermore, gene expression profiling analysis revealed overexpression of MALAT1 mRNA in colorectal cancer tissue compared with normal controls. Confirmation studies with large sample size and further mechanistic investigations into the function of MALAT1 and its genetic variants are warranted to advance our understanding of their roles in colorectal carcinogenesis, and to aid in the development of novel and targeted therapeutic strategies.

\section{MATERIALS AND METHODS}

\section{Study subjects}

This study was approved by the Medical Ethical Committee of Zhejiang University School of Medicine. All subjects enrolled were heritably unrelated ethnic Han Chinese. Details of the study population including recruitment details and participant characteristics have been described previously [42]. In brief, the registry information of this population was initially collected for a cohort study on CRC in 1989 in Jiashan County, Zhejiang
Province, China. Meanwhile a cancer surveillance and registry system covering the whole county was established for reporting new cancer patients of $\mathrm{CRC}$ and all other kinds of cancers. Although there were no restrictions on patients' age, gender or tumor stage, only those patients who were incident and histologically confirmed CRC, living in the study geographic area, mentally competent to complete the interview and with no previous diagnosis of familial adenomatous polyposis, ulcerative colitis or Crohn's disease were included in our study. Healthy controls with no previous history of cancer were recruited in parallel from the same population and were matched to cases by age ( \pm 5 years), gender and residential area. In total, $821 \mathrm{CRC}$ cases and 857 healthy controls were recruited in two stages (320 cases and 319 controls for the Stage 1 which was recruited from 2012 to 2014, with additional 501 cases and 538 controls for the Stage 2 which was recruited from 2002 to 2010). Before participation, written informed consent was obtained from all the study subjects. Face-to-face interviews were conducted by trained interviewers, who administered a structured questionnaire relating to demographic characteristics and lifestyle-related factors. After interview, $5 \mathrm{ml}$ blood sample was collected into sodium citrate anticoagulant tubes and stored at $-80^{\circ} \mathrm{C}$ for DNA isolation. Genomic DNA was isolated from peripheral blood samples for each study subject using the modified salting-out procedure [43].

CRC tissues from a total of 71 patients who had undergone curative surgery at Department of Gastrointestinal surgery, Hangzhou First People's Hospital were collected from July 2013 to December 2013. All the patients were pathologically confirmed as colorectal adenocarcinoma. The ttissues were immediately preserved in RNA Later ${ }^{\circledR}$ Stabilization Solution (Invitrogen, Carlsbad, CA, USA) after removal from the body and stored at $-80^{\circ} \mathrm{C}$.

\section{SNP selection and genotyping}

We selected the tagSNPs which were located in $2000 \mathrm{bp}$ upstream region of MALAT1 with minor allele frequencies $(\mathrm{MAF})>0.10$ in Han Chinese Beijing from the 1000 Genome Projects. We also amplify the region to $5000 \mathrm{bp}$ as SNPs in this region could regulate gene expression by remote controlling the promoter region [44]. As a result, four tagSNPs (rs4102217, rs591291, rs1194338 and rs600231) were selected when linkage disequilibrium (LD) between pair-wise SNPs was with a minimum $r^{2}$ of 0.80 . Genotyping for all polymorphisms was performed by the MassARRAY molecular weight array analysis system (BioMiao Biological Technology Co., Beijing, China). Five percentage of samples were randomly selected for repeated detection and the concordance rate was $>99 \%$. 


\section{RNA isolation and quantitative RT-PCR}

Total cellular RNA was isolated from each sample using a homogenizer (IKA ${ }^{\circledR}$-Works Guangzhou, China) and TRIzol reagent (Invitrogen) and then purified using the RNeasy Mini Kit (Qiagen, Hilden, Germany) according to the manufacturer's protocol. A reverse transcription real-time PCR (RT-PCR) was conducted employing StepOnePlus instrument (Applied Biosystems, Foster City, CA, USA) to quantify relative MALAT1 expression in these samples. The specific forward primer and reverse primer used for quantitative RT-PCR were 5'-TCCCTCAAGAGAACACAAGAAG-3' and 5'-GGCGTATTTATAGACGGAGAAC-3'. The $\beta$-actin was selected as the endogenous control. The specific forward primer and reverse primer were 5'-GTGGCCGAGGACTTTGATTG-3' and 5'-CCTGTAA CAACGCATCTCATATT-3'. We performed real-time PCR in StepOnePlus Real- Time PCR System (Applied Biosystems, Foster City, CA, USA) using SYBR Green Master Mix (Vazyme, Nanjing, China). All procedures were carried out in triplicate.

\section{Bioinformatics analysis}

Furthermore, we applied several semi-automated bioinformatics tools to explore whether SNPs or their linked genetic variants are associated with a potential function that might affect the cancer development and progression. HaploReg [45] v4 and the GTEx database [26] from the ENCODE project [46] were used to identify the regulatory potential of candidate functional variants. The GTEx data were used to identify correlations between SNPs and transverse colon-specific gene expression levels.

\section{Expression analysis in colorectal cancer tissue}

To determine the expression pattern of MALAT1 in CRC, 20 probe comparisons in 10 studies, including Kaiser Colon [47], TCGA Colorectal (http://tcga-data. nci.nih.gov/tcga/), Zou Colon [48], Gaspar Colon [49], Graudens Colon [50], Hong Colorectal [51], Skrzypczak Colorectal [52], Skrzypczak Colorectal 2 [52], SabatesBellver Colon [53], Gaedcke Colorectal [54] from the publicly available cancer microarray database Oncomine (https://www.oncomine.org/; accessed on February 05, 2017) were used. The gene expression of MALAT1 was compared between CRC tissues with normal tissues according to the standard procedures as previously described [55]. Volcano plots were generated using the $P$ value and fold-change of each probe comparison. Detailed information regarding the experimental protocols and tissue samples can be found in the Oncomine database.

\section{Statistical analysis}

Differences in the distribution of selected demographic variables and genotypes of tagSNPs were evaluated by Pearson's chi-square test. Hardy-Weinberg equilibrium for each SNP among controls was tested using a goodness-of-fit chi-square test. The associations of each SNP and CRC susceptibility were estimated by using unconditional logistic regression analyses with odds ratios (ORs) and 95\% confidence intervals (CIs). Multiple genetic models (codominant, dominant and recessive models) were applied to assess the significance of SNPs. Those tagSNPs with a $P$ value less than 0.20 in Stage 1 were further studied in Stage 2. Pooled-analyses were conducted to estimate the combined effect of the two stages. The relative expression levels of MALAT1 in 71 $\mathrm{CRC}$ tissues were calculated by the following formula: (levels of MALAT1-levels of $\beta$-actin)/ levels of $\beta$-actin. The one-way analysis of variance was applied to test statistically difference among the expression of MALAT1 with diverse rs 1194338 genotypes. A $P$-value of less than 0.05 for two-side was considered statistically significant. All analyses were conducted with SAS 9.2 software (SAS Institute, Cary, NC, USA) and Stata 11.2 (STATA Corp, College Station, Texas).

\section{CONFLICTS OF INTEREST}

The authors declared no conflicts of interest.

\section{FUNDING}

This study was partly supported by National Natural Science Foundation of China (No.81373087), National Key Basic Research Program (973 program No.2015CB554003), Medical Science and Technology Project of Zhejiang Province (No.2017203626), and Research on the Application of Public Welfare Technology of Zhejiang Province (No.2014C33224).

\section{REFERENCES}

1. Derrien T, Johnson R, Bussotti G, Tanzer A, Djebali S, Tilgner H, Guernec G, Martin D, Merkel A, Knowles DG, Lagarde J, Veeravalli L, Ruan XA, et al. The GENCODE v7 catalog of human long noncoding RNAs: analysis of their gene structure, evolution, and expression. Genome Res. 2012; 22:1775-1789.

2. Bai Y, Nie S, Jiang G, Zhou Y, Zhou M, Zhao Y, Li S, Wang F, Lv Q, Huang Y, Yang Q, Li Q, Li Y, et al. Regulation of CARD8 expression by ANRIL and association of CARD8 single nucleotide polymorphism rs2043211 (p.C10X) with ischemic stroke. Stroke. 2014; 45:383-388.

3. Schonrock N, Götz J. Decoding the non-coding RNAs in Alzheimer's disease. Cell Mol Life Sci. 2012; 69:3543-3559.

4. Xiao XG, Touma M, Wang Y. Decoding the noncoding transcripts in human heart failure. Circulation. 2014; 129:958-960. 
5. Huang T, Alvarez A, Hu B, Cheng SY. Noncoding RNAs in cancer and cancer stem cells. Chin J Cancer. 2013; 32:582-593.

6. Schmitt AM, Chang HY. Gene regulation: long RNAs wire up cancer growth. Nature. 2013; 500:536-537.

7. Ji P, Diederichs S, Wang W, Böing S, Metzger R, Schneider PM, Tidow N, Brandt B, Buerger H, Bulk E. MALAT-1, a novel noncoding RNA, and thymosin $\beta 4$ predict metastasis and survival in early-stage non-small cell lung cancer. Oncogene. 2003; 22:8031-8041.

8. Schmidt LH, Spieker T, Koschmieder S, Humberg J, Jungen D, Bulk E, Hascher A, Wittmer D, Marra A, Hillejan L. The long noncoding MALAT-1 RNA indicates a poor prognosis in non-small cell lung cancer and induces migration and tumor growth. J Thorac Oncol. 2011; 6:1984-1992.

9. Zhou X, Liu S, Cai G, Kong L, Zhang T, Ren Y, Wu Y, Mei M, Zhang L, Wang X. Long non coding RNA MALAT1 promotes tumor growth and metastasis by inducing epithelial-mesenchymal transition in oral squamous cell carcinoma. Sci Rep. 2015; 5:15972.

10. Liu J, Peng W, Mo Y, Luo D. MALAT1-mediated tumorigenesis. Front Biosci (Landmark Ed). 2017; 22:66-80.

11. Malakar P, Shilo A, Mogilevsky A, Stein I, Pikarsky E, Nevo Y, Benyamini H, Elgavish S, Zong X, Prasanth KV, Karni R. Long noncoding RNA MALAT1 promotes hepatocellular carcinoma development by SRSF1 upregulation and mTOR activation. Cancer Res. 2016; 77:1155-1167.

12. Lee NK, Lee JH, Ivan C, Ling H, Zhang X, Park CH, Calin GA, Lee SK. MALAT1 promoted invasiveness of gastric adenocarcinoma. BMC Cancer. 2017; 17:46.

13. Wang SH, Zhang WJ, Wu XC, Zhang MD, Weng MZ, Zhou D, Wang JD, Quan ZW. Long non-coding RNA Malat1 promotes gallbladder cancer development by acting as a molecular sponge to regulate miR-206. Oncotarget. 2016; 7:37857-37867. https://doi.org/10.18632/oncotarget.9347.

14. Ji Q, Zhang L, Liu X, Zhou L, Wang W, Han Z, Sui H, Tang Y, Wang Y, Liu N, Ren J, Hou F, Li Q. Long non-coding RNA MALAT1 promotes tumour growth and metastasis in colorectal cancer through binding to SFPQ and releasing oncogene PTBP2 from SFPQ/PTBP2 complex. Br J Cancer. 2014; 111:736-748

15. Yang MH, Hu ZY, Xu C, Xie LY, Wang XY, Chen SY, Li ZG. MALAT1 promotes colorectal cancer cell proliferation/ migration/invasion via PRKA kinase anchor protein 9. Biochim Biophys Acta. 2015; 1852:166-174.

16. Hindorff LA, Sethupathy P, Junkins HA, Ramos EM, Mehta JP, Collins FS, Manolio TA. Potential etiologic and functional implications of genome-wide association loci for human diseases and traits. Proc Natl Acad Sci U S A. 2009; 106:9362-9367.

17. Gong J, Tian J, Lou J, Ke J, Li L, Li J, Yang Y, Gong Y, Zhu Y, Zhang Y, Zhong R, Chang J, Miao X. A functional polymorphism in lnc-LAMC2-1:1 confers risk of colorectal cancer by affecting miRNA binding. Carcinogenesis. 2016; 37:443-451.

18. Al-Tassan NA, Whiffin N, Hosking FJ, Palles C, Farrington SM, Dobbins SE, Harris R, Gorman M, Tenesa A, Meyer BF, Wakil SM, Kinnersley B, Campbell H, et al. A new GWAS and meta-analysis with 1000Genomes imputation identifies novel risk variants for colorectal cancer. Sci Rep. 2015; 5:10442.

19. Xue Y, Gu D, Ma G, Zhu L, Hua Q, Chu H, Tong N, Chen J, Zhang Z, Wang M. Genetic variants in IncRNA HOTAIR are associated with risk of colorectal cancer. Mutagenesis. 2015; 30:303-310.

20. Gong WJ, Yin JY, Li XP, Fang C, Xiao D, Zhang W, Zhou $\mathrm{HH}$, Li X, Liu ZQ. Association of well-characterized lung cancer lncRNA polymorphisms with lung cancer susceptibility and platinum-based chemotherapy response. Tumour Biol. 2016; 37:8349-8358.

21. Zhuo Y, Zeng Q, Zhang P, Li G, Xie Q, Cheng Y. Functional polymorphism of IncRNA MALAT1 contributes to pulmonary arterial hypertension susceptibility in Chinese people. Clin Chem Lab Med. 2017; 55:38-46.

22. Yang L, Yang X, Ji W, Deng J, Qiu F, Yang R, Fang W, Zhang L, Huang D, Xie C, Zhang H, Zhong N, Ran P, et al. Effects of a functional variant c.353T $>$ C in snail on risk of two contextual diseases. Chronic obstructive pulmonary disease and lung cancer. Am J Respir Crit Care Med. 2014; 189:139-148.

23. Styrkarsdottir U, Thorleifsson G, Gudjonsson SA, Sigurdsson A, Center JR, Lee SH, Nguyen TV, Kwok TC, Lee JS, Ho SC. Sequence variants in the PTCH1 gene associate with spine bone mineral density and osteoporotic fractures. Nat Commun. 2016; 7:10129.

24. Boersma BJ, Howe TM, Goodman JE, Yfantis HG, Lee DH, Chanock SJ, Ambs S. Association of breast cancer outcome with status of p53 and MDM2 SNP309. J Natl Cancer Inst. 2006; 98:911-919.

25. LeVan TD, Bloom JW, Bailey TJ, Karp CL, Halonen M, Martinez FD, Vercelli D. A common single nucleotide polymorphism in the CD14 promoter decreases the affinity of Sp protein binding and enhances transcriptional activity. J Immunol. 2001; 167:5838-5844.

26. Consortium GT. The Genotype-Tissue Expression (GTEx) project. Nat Genet. 2013; 45:580-585.

27. Fitzmaurice C, Dicker D, Pain A, Hamavid H, MoradiLakeh M, MacIntyre MF, Allen C, Hansen G, Woodbrook R, Wolfe C, Hamadeh RR, Moore A, Werdecker A, et al, Global Burden of Disease Cancer Collaboration. The global burden of cancer 2013. JAMA Oncol. 2015; 1:505-527.

28. Grade M, Becker H, Liersch T, Ried T, Ghadimi BM. Molecular cytogenetics: genomic imbalances in colorectal cancer and their clinical impact. Anal Cell Pathol. 2006; 28:71-84. 
29. Sarkar D, Leung EY, Baguley BC, Finlay GJ, AskarianAmiri ME. Epigenetic regulation in human melanoma: past and future. Epigenetics. 2015; 10:103-121.

30. Kogo R, Shimamura T, Mimori K, Kawahara K, Imoto S, Sudo T, Tanaka F, Shibata K, Suzuki A, Komune S, Miyano $\mathrm{S}$, Mori M. Long noncoding RNA HOTAIR regulates polycomb-dependent chromatin modification and is associated with poor prognosis in colorectal cancers. Cancer Res. 2011; 71:6320-6326.

31. Yang L, Lin C, Jin C, Yang JC, Tanasa B, Li W, Merkurjev D, Ohgi KA, Meng D, Zhang J. IncRNA-dependent mechanisms of androgen-receptor-regulated gene activation programs. Nature. 2013; 500:598-602.

32. Matouk IJ, Halle D, Raveh E, Gilon M, Sorin V, Hochberg A. The role of the oncofetal H19 lncRNA in tumor metastasis: orchestrating the EMT-MET decision. Oncotarget. 2016; 7:3748. https://doi.org/10.18632/ oncotarget.6387.

33. Gutschner T, Hämmerle M, Eißmann M, Hsu J, Kim Y, Hung G, Revenko A, Arun G, Stentrup M, Groß M. The noncoding RNA MALAT1 is a critical regulator of the metastasis phenotype of lung cancer cells. Cancer Res. 2013; 73:1180-1189.

34. Tripathi V, Shen Z, Chakraborty A, Giri S, Freier SM, Wu X, Zhang Y, Gorospe M, Prasanth SG, Lal A. Long noncoding RNA MALAT1 controls cell cycle progression by regulating the expression of oncogenic transcription factor B-MYB. PLoS Genet. 2013; 9:e1003368.

35. Pandey GK, Mitra S, Subhash S, Hertwig F, Kanduri M, Mishra K, Fransson S, Ganeshram A, Mondal T, Bandaru $\mathrm{S}$. The risk-associated long noncoding RNA NBAT-1 controls neuroblastoma progression by regulating cell proliferation and neuronal differentiation. Cancer Cell. 2014; 26:722-737.

36. De Vooght KM, Van Wijk R, Van Solinge WW. Management of gene promoter mutations in molecular diagnostics. Clin Chem. 2009; 55:698-708.

37. Hoogendoorn B, Coleman SL, Guy CA, Smith SK, O'Donovan MC, Buckland PR. Functional analysis of polymorphisms in the promoter regions of genes on $22 \mathrm{q} 11$. Human Mutat. 2004; 24:35-42.

38. Wills QF, Livak KJ, Tipping AJ, Enver T, Goldson AJ, Sexton DW, Holmes C. Single-cell gene expression analysis reveals genetic associations masked in whole-tissue experiments. Nat Biotechnol. 2013; 31:748-752.

39. Fairfax BP, Humburg P, Makino S, Naranbhai V, Wong D, Lau E, Jostins L, Plant K, Andrews R, McGee C, Knight JC. Innate immune activity conditions the effect of regulatory variants upon monocyte gene expression. Science. 2014; 343:1246949.

40. Markowitz SD, Bertagnolli MM. Molecular origins of cancer: molecular basis of colorectal cancer. N Engl J Med. 2009; 361:2449-6037.
41. Friederichs J, Rosenberg R, Mages J, Janssen KP, Maeckl C, Nekarda H, Holzmann B, Siewert JR. Gene expression profiles of different clinical stages of colorectal carcinoma: toward a molecular genetic understanding of tumor progression. Int J Colorectal Dis. 2005; 20:391-402.

42. Zhang Y, Liu B, Jin M, Ni Q, Liang X, Ma X, Yao K, Li Q, Chen K. Genetic polymorphisms of transforming growth factor- $\beta 1$ and its receptors and colorectal cancer susceptibility: a population-based case-control study in china. Cancer Lett. 2009; 275:102-108.

43. Nasiri H, Forouzandeh M, Rasaee MJ, Rahbarizadeh F. Modified salting-out method: high-yield, high-quality genomic DNA extraction from whole blood using laundry detergent. J Clin Lab Anal. 2005; 19:229-232.

44. Zhang D, Cheng L, Badner JA, Chen C, Chen Q, Luo W, Craig DW, Redman M, Gershon ES, Liu C. Genetic control of individual differences in gene-specific methylation in human brain. Am J Hum Genet. 2010; 86:411-419.

45. Ward LD, Kellis M. HaploReg v4: systematic mining of putative causal variants, cell types, regulators and target genes for human complex traits and disease. Nucleic Acids Res. 2016; 44:D877-D881.

46. Pazin MJ. Using the ENCODE resource for functional annotation of genetic variants. Cold Spring Harb Protoc. 2015; 2015:522-536.

47. Kaiser S, Park YK, Franklin JL, Halberg RB, Yu M, Jessen WJ, Freudenberg J, Chen XD, Haigis K, Jegga AG, Kong $\mathrm{S}$, Sakthivel B, Xu H, et al. Transcriptional recapitulation and subversion of embryonic colon development by mouse colon tumor models and human colon cancer. Genome Biol. 2007; 8:R131.

48. Zou TT, Selaru FM, Xu Y, Shustova V, Yin J, Mori Y, Shibata D, Sato F, Wang SM, Olaru A, Deacu E, Liu TC, Abraham JM, Meltzer SJ. Application of cDNA microarrays to generate a molecular taxonomy capable of distinguishing between colon cancer and normal colon. Oncogene. 2002; 21:4855-4862.

49. Gaspar C, Cardoso J, Franken P, Molenaar L, Morreau H, Moslein G, Sampson J, Boer JM, de Menezes RX, Fodde R. Cross-species comparison of human and mouse intestinal polyps reveals conserved mechanisms in adenomatous polyposis coli (APC)-driven tumorigenesis. Am J Pathol. 2008; 172:1363-1380.

50. Graudens E, Boulanger V, Mollard C, Mariage-Samson R, Barlet X, Gremy G, Couillault C, Lajemi M, PiatierTonneau D, Zaborski P, Eveno E, Auffray C, Imbeaud S. Deciphering cellular states of innate tumor drug responses. Genome Biol. 2006; 7:R19.

51. Hong Y, Downey T, Eu KW, Koh PK, Cheah PY. A 'metastasis-prone' signature for early-stage mismatchrepair proficient sporadic colorectal cancer patients and its implications for possible therapeutics. Clin Exp Metastasis. 2010; 27:83-90. 
52. Skrzypczak M, Goryca K, Rubel T, Paziewska A, Mikula M, Jarosz D, Pachlewski J, Oledzki J, Ostrowsk J. Modeling oncogenic signaling in colon tumors by multidirectional analyses of microarray data directed for maximization of analytical reliability. PLoS One. 2010; 5:e13091.

53. Sabates-Beliver J, Van der Flier LG, de Palo M, Cattaneo E, Maake C, Rehrauer H, Laczko E, Kurowski MA, Bujnicki JM, Menigatti M, Luz J, Ranalli TV, Gornes V, et al. Transcriptome profile of human colorectal adenomas. Mol Cancer Res. 2007; 5:1263-1275.

54. Gaedcke J, Grade M, Jung K, Camps J, Jo P, Emons G, Gehoff A, Sax U, Schirmer M, Becker H, Beissbarth T, Ried
T, Ghadimi BM. Mutated KRAS results in overexpression of DUSP4, a MAP-kinase phosphatase, and SMYD3, a histone methyltransferase, in rectal carcinomas. Genes Chromosomes Cancer. 2010; 49:1024-1034.

55. Rhodes DR, Kalyana-Sundaram S, Mahavisno V, Varambally R, Yu J, Briggs BB, Barrette TR, Anstet MJ, Kincead-Beal C, Kulkarni P, Varambally S, Ghosh D, Chinnaiyan AM. Oncomine 3.0: genes, pathways, and networks in a collection of 18,000 cancer gene expression profiles. Neoplasia. 2007; 9:166-180. 